\title{
Mathematical Modeling of Knowledge-Intensive Products Export Energy Costs
}

\author{
VERETEKHINA SVETLANA V. \\ Doctoral program Financial University under the Government of the Russian Federation, Faculty of \\ Information Technologies Russian State Social University \\ Wilhelm Pieck street, 4, build.1, Moscow, 129226
}

RUSSIA

\begin{abstract}
This article presents the mathematical modeling of export energy costs. The knowledge-intensive products export energy costs are a set of financial, material, labor costs and resources consumption. Export costs are a multilevel system of indicators. The author sets out the order of mathematical modeling. At the first stage, the main trends in reducing export energy costs are identified. A set of integrated logistics support measures is modeled. The modeling of knowledge-intensive products export energy costs is a system of technical and economic indices and a cost value dependance: Maintenance and Repair, Material and Technical Maintenance, Business Model of After-Sales Service, Formation of the Cost of Insurance and Investment Management Strategy. Formulas, practical calculation examples and graphs are presented. The Ishikawa systematic analysis method is used to visualize data and dependence relations. The author's mathematical modeling of knowledge-intensive products export costs includes the calculation of integrated logistic support costs. Exporting countries require a high level of technical products efficiency. It has been established that "the more complex a knowledge-intensive products is, the higher the reliability of systems is". Reliability indices are basic. The author's scientific study confirms a hypothesis of the knowledge-intensive products export feasibility only with high reliability and efficiency factors. The author developed a set of integrated logistical support measures for knowledge-intensive products.
\end{abstract}

Keywords: mathematical modeling, systematic analysis, export problems, integrated logistics support, technical and economic indices.

Received: March 2, 2021. Revised: November 15, 2021. Accepted: December 17, 2021. Published: January 5, 2022.

\section{Introduction}

The knowledge-intensive products export energy costs are understood as a set of financial, material, labor costs and resources consumption. Exporting countries require a high level of technical products efficiency. To ensure a high level of technical readiness, it is necessary to calculate the cost of material and technical support, the cost of repair spare parts, salaries for technical staff, consumable resources, electrical energy or alternative power supplies. The cost of knowledge-intensive products in the international market does not dominate [1]. The presence of integrated logistics support dominates, including the optimization of financial, material, labor costs and resources. In other words, knowledge-intensive products cost is estimated in millions of dollars, and integrated logistics support cost throughout the products life cycle is estimated in hundreds of millions of dollars [2]. The life cycle of technical products is from 15 to 70 years. In case of long life cycles, the integrated logistics support cost is high. It is necessary to find ways to optimize it. Therefore, it is necessary to carry out mathematical modeling to optimize the knowledgeintensive products export energy costs. In the study by Boitsov M.S. et al. "Energy Costs as a Manageable Economic Category" organizational and economic measures to improve energy efficiency are described [3]. Cost management is an ability to save resources. Energy efficiency management is a resource economy. Integrated logistics support is a set of measures aimed at modeling the knowledge-intensive products aftersales maintenance situation. Information support for complex technical systems is becoming topical. This is due to the exports growth. Aftersales maintenance is a modern international service market. Such services as export, maintenance, integrated logistics support are standardized. Standardization is regulated by country regulatory and legislative documents. Different countries have their own individual natural resources: industrial 
water, electrical energy, fuel, transport infrastructure, roads, logistics warehouses, technical staff. The use of all resource types and the cost of their use are modeled during integrated logistics support measures development. To carry out mathematical modeling of export energy costs value, we will determine the main trends of integrated logistics support.

The advantage of this study is the identification of problems of knowledge-intensive product exports (paragraphs $2.1 .1 ; 2.12 ; 2.1 .3 ; 2.1 .4$ ). Mathematical tools for calculating technical and economic indicators are proposed in order to solve the identified problems. The main indicator for the export of knowledge-intensive products is the reliability indicator. The more reliable the product is, the more efficiently all functions are performed. Therefore, the proposed formulas (1)-(8), allows to calculate the performance of the product on a long life cycle. Mathematical modeling of a large number of indicators was carried out by the method of system analysis. The advantage of this research is the functional and system analysis of interdependent indicators. The simulation method chose such an interval of the normative duration of the intended use of the product that the probability values are low (see Table 2). This indicates that the tactical and technical characteristics of a knowledge-intensive product were chosen correctly when designing the product. The author has developed a set of actions for integrated logistics support for knowledgeintensive products, taking into account the calculated coefficients showing high accuracy.

\section{Problems and Trends of Export Energy Costs}

The main trends in reducing export energy costs include:

1. reducing the excess quantity of spare parts for technical repair, determining the minimum required and sufficient quantity of stock elements;

2. using the existing repair and mechanical shops of exporting countries;

3. dividing the after-sale maintenance stages into several parts: operation, warranty and post-warranty maintenance, repair; each stage is paid under a separate international contract;
4. outsourcing the Maintenance and Repair and Material and Technical Support procedures;

5. optimizing the export costs through mathematical modeling.

Export energy costs are limited by budget. The development of integrated logistics support measures for exports is based on modeling the optimal stock maintenance processes in an exporting country by and at the cost of a manufacturing country, an exporting country and friendly countries. Foreign export customers insure orders (purchases) against losses. Insurance is applicable to the following types of losses: transportation; stock maintenance; downtime and unserviceability of knowledge-intensive products; low level of maintenance and repair; low level of technical staff human potential. In the field of exports, there is a proverb "If you need one supercomplex and unique thing, then contact the Russians, if you need 10 identical things, never contact them" http://exportcenter.rbc.ru/article-5-ideas.html.

Russia is a country with its own knowledgeintensive products engineering and strong engineering and design thought. Russia exports devices and equipment, power plants, detection stations, aircrafts, ships and other products. All these products are knowledge-intensive.

We will analyze the knowledge-intensive products exporting problems.

Export problems are those related to the Russian foreign trade at the modern level. In the study by Ruzhinskaya T.I "Problems of the Russian foreign trade at the present stage" the main problems of exports are specified [4].

\subsection{Problems of Knowledge-Intensive Products Export}

Export problems are those related to the Russian foreign trade at the modern level. In the study by Ruzhinskaya T.I "Problems of the Russian foreign trade at the present stage" the export earnings status is analyzed and new service export areas are specified [4]. As can be seen from the main trends in reducing energy export costs, the sale of after-sale maintenance services (operation, warranty and post-warranty maintenance, repair) is paid under a separate international contract. The cost of after-sale 
maintenance services for knowledge-intensive products in an exporting country is estimated in hundreds of millions of dollars with a long product life cycle. Power plants, early-warning stations, ships and aircrafts serve in an exporting country for decades. Knowledgeintensive products ensure the stability of development in an exporting country. Foreign trade in knowledge-intensive products is intended for China, Indonesia, Malaysia, India, Syria, France and the Near East.

\subsubsection{Formation of the Maintenance and Repair Cost}

The first problem of exporting knowledgeintensive products is a customer's ability to choose the cost of Maintenance and Repair (M\&R). Maintenance and repair services can be performed by product developers, manufacturers or third-party international enterprises. The application of the Maintenance and Repair service requires the interactive electronic technical manuals development (IETM), electronic catalogs of spare parts and accessories. The availability of technical documents allows technical staff to carry out such activities as operation, maintenance and repair. Modern interactive electronic manuals are made in 5 complexity classes:

1. scanned pages of paper documents;

2. a set of texts in the SGML format;

3. data as objects within an information storage that has a hierarchical structure;

4. direct interface interaction with electronic modules for product diagnostics;

5. 5. integration with expert systems. An international standard for interactive electronic technical manuals is the S1000D Specification.

The development of classes 4 and 5 interactive electronic technical manuals is provided for export products. The main advantage of interactive electronic technical manuals is an automated translation of technical documents into such languages as Arabic, English, Spanish, Sino-Malaysian in real time. The automated system visualizes the location of texts and symbols according to the documents linguistics and spelling rules for words and sentences. In addition, there are such options as animated display, multimedia assembly (dismantling) of product component parts, blocks, units and mechanisms. The cost of developing interactive electronic technical manuals is included in a set of integrated logistics support measures for knowledgeintensive products. It is paid by the customer separately, under a contract related to the development of technical operation documents. The generation of the Maintenance and Repair cost includes calculations of material, labor, financial resources. The Maintenance and Repair cost is included in a set of integrated logistics support measures for knowledgeintensive products.

\subsubsection{Formation of the Material and Technical Maintenance Cost}

The second export problem is the planning and management of Material and Technical Maintenance (MTM) processes. The MTM management includes:

1. spare parts planning needs and spare parts consumption forecast;

2. management algorithms for warehouse stocks;

3. procurement management;

4. supplies transportation and delivery organization, options for the element distribution in repair and mechanical shops, warehouse distribution; storage;

5. resources replenishment; resources extension;

6. issue records for supplies, issue records for spare parts (electronic catalogs); report generation.

The Material and Technical Maintenance cost formation includes calculations of a resources cost, a maintenance and application cost for each resource type. The Material and Technical Maintenance cost is included in a set of integrated logistics support measures for knowledge-intensive products.

\subsubsection{Formation of an After-Sales Service Business Model}

Exporting countries impose requirements for aftersales service business model organization. Integrated logistics support includes typical business models for supplier-customer interaction. The confluence of supplier and customer interests is 
reflected in export contracts. The main international standards are as follows: DEF STAN 00-60, MIL STD-1390D (used by the Indian Navy), STANAG 4427 (configuration management for supplied products), MIL-STD 1369, SPEC 1000D, SPEC 2000M, SPEC S3000L (LSA), SPEC S4000M. An individual business model for a certain exporting country requires the development of:

1. management methods and technologies for stocks, orders, supplies of spare parts, accessories and repair consumables;

2. management methods and technologies for Material and Technical Maintenance;

3. management methods and technologies for Maintenance and Repair (M\&R);

4. standardization of procedures and technologies, harmonization of data and document exchange formats.

The After-Sales Service Business Model cost includes calculations for the management methods and technologies development . The After-Sales Service Business Model cost is included in a set of integrated logistics support measures for knowledge-intensive products.

\subsubsection{Formation of an Investment Management Strategy}

Exporting countries impose investment management requirements for the organization. Integrated logistics support includes investment management for spare parts replenishment, specifically:

1. a strategy for maximum financial management;

2. a direct strategy;

3. a strategy for a consolidated balance sheet.

A maximum financial management strategy suggests that: a budget is divided into parts, only a 1/12 (12 months a year) part of the budget can be spent within one period of time. The maximum financial management strategy is considered to be an operator, it neglects the stochastic nature of demand and consumption. A lack of this maximum financial management strategy results in a situation where a budget is not used to the maximum extent and has certain restrictions.

A direct strategy is each request for a spare parts catalog item, which results in its order and a full payment. There are no time or cost restrictions when it comes to an order item. There is no hindrance to the budget spending. A lack of this direct strategy results in a possible lack of budget and stocks (shortage), leads to an imbalance in supporting the efficiency of knowledge-intensive products.

A consolidated balance sheet strategy combines the advantages of both maximum financial management and direct strategies. It prevents any stock instability at the end of the budget year. The main idea of this consolidated balance sheet strategy is a maximum balance in stocks.

We can draw the following conclusions: efficient stock management and resource optimization require the development of conceptual and functional integrated logistics support schemes for knowledge-intensive products. Integrated logistics support measures are based on the principle of central management. The development of a set of integrated logistics support measures is aimed at improving the efficiency of after-sales service for knowledge-intensive products. The efficiency of a set of integrated logistics support measures is based on the global information network, which allows for operational management. Information and computer support is an integral part of a measure effectiveness set. The reliable functioning of information and computer support ensures timely operational interaction in logistics objectives by supply chains. The authors study of system integrated logistics support in military products considers additional features of after-sales service organization for knowledge-intensive products [5].

\subsubsection{Formation of the Insurance Cost}

Foreign export customers insure orders (purchases) against losses. Insurance is applicable to the following types of losses: transportation; stock maintenance; downtime and unserviceability of knowledge-intensive products; low level of maintenance and repair; low level of technical staff human potential. The exporter's insurance support is the provision of insurance tools to protect export credits and investments, which includes:

1. deferred payments insurance;

2. deferral insurance (insurance indemnity);

3. credit insurance to replenish the exporter's circulating assets;

4. export factoring insurance (a risk factor of non-payment);

5. Russian outward investments insurance;

6. short-term accounts receivable insurance;

7. supplier's credit insurance against a risk of a foreign buyer's payment failure.

In addition, export control procedures related to foreign economic activities are accompanied and supported. Methodological support in the currency control field allows us to comply with the foreign exchange legislation requirements for the currency earnings repatriation. Methodological support in the currency control field includes the exporters responsibility for violating the foreign exchange legislation requirements, analyzing sanctions, 
minimizing risks, as well as interacting with an authorized bank.

The identified Maintenance and Repair, Material and Technical Maintenance, Business Model of After-Sales Service, Formation of the Cost of Insurance and Investment Management Strategy cost value formation problems show a necessity for systematic analysis. Integrated logistics support measures systematic analysis. The modeling of the exporting knowledge-intensive products energy costs is a system of technical and economic indicators and costs dependence. The more complex a knowledge-intensive product is and the higher the systems reliability is, the higher the total cost of integrated logistics support is. Let us try to identify main mathematical dependencies.

\section{Mathematical Modeling of Export Energy Costs m Solution}

It has been established that "the more complex a knowledge-intensive product is and the higher the systems reliability is", reliability indices are basic.

\subsection{System Reliability, System Failure Interval}

3.1 Reliability requirements distribution and a calculation method for the "average system failure interval" coefficient (for one system element):

$\mathrm{T}_{0}=\mathrm{T}_{0 \mathrm{k}} \cdot 1 /\left(\gamma^{\mathrm{n}}(\mathrm{n}+1) ! \mathrm{C}^{\mathrm{n}+1} \mathrm{~N}\right)$

where $\mathrm{T}_{0 \mathrm{k}}$ is a system element failure interval; $\gamma$ is a ratio of the system element recovery time and system failure interval; $\mathrm{n}$ is an allowed number of system elements that are simultaneously in a state of failure.

\subsection{Technical Readiness and Availability Coefficients}

Technical readiness coefficient characterizing the sample readiness depending on the failure-free operation and labor intensity of maintenance and repair is calculated according to the formula:

$$
\mathrm{K}_{\mathrm{tr}}=\mathrm{K}_{\mathrm{au}} * \mathrm{~K}_{\mathrm{pa}}
$$

where $K_{a u}$ is an indicator (availability coefficient is a probability that the planned time of sample intended use will not be delayed beyond the permissible time or canceled due to failure); $K_{p a}$ is an indicator (planned applicability coefficient is a proportion of operation definite period during which the product is not under planned maintenance and repair).

$\mathrm{K}_{\mathrm{pa}}=1-\mathrm{K}_{\mathrm{d}} * \tau$ where $\tau$ - severity of use defined as a ratio of product operating time during its intended use (in hours, kilometers, starts, cycles, shots, etc.) per calendar year and an estimated annual time reserve (in hours); $\mathrm{K}_{\mathrm{d}}$ is a sum of specific aggregate duration of planned maintenance category $\mathrm{K}_{\mathrm{dm}}$ and specific aggregate duration of recovery $\mathrm{K}_{\mathrm{dr}}$

$\mathrm{K}_{\mathrm{d}}=\mathrm{K}_{\mathrm{dm}}+\mathrm{K}_{\mathrm{dr}}$

where $\mathrm{K}_{\mathrm{dm}}$ is the specific maintenance (repair) duration, a ratio of the total maintenance (repair) duration mathematical expectation and the sample operating time during its intended use for a certain operation period; $\mathrm{K}_{\mathrm{dr}}$ is specific recovery duration.

The $K_{p a}, K_{d}, K_{\text {tr }}$ coefficients are determined at the estimated (normalized) operation intensity based on actual operation data. The $\mathrm{K}_{\mathrm{au}}$ indicator (availability coefficient is a probability that the planned time of sample intended use will not be delayed beyond the permissible time or canceled due to failure) is evaluated according to the formula:

$$
\mathrm{K}_{\mathrm{au}}=\mathrm{K}_{\mathrm{a}}+\left(1-\mathrm{K}_{\mathrm{a}}\right)^{*} \mathrm{P}_{\mathrm{r}} \text {, }
$$

where $P_{r}$ is a probability of the sample recovery at a given time during its preparation for intended use; $\mathrm{K}_{\mathrm{a}}$ is an availability factor.

This probability of the sample recovery at a given time is determined taking into account the standard duration of preparation for intended use, the permissible time for delaying the start of use taking into account the possibility of intended use with separate failures according to the following formulas:

$P_{\mathrm{r}}=1-\exp \left(-\mathrm{t}_{\mathrm{p}} / \mathrm{t}_{\mathrm{r}}\right)$,

$t_{\mathrm{p}}=\mathrm{t}_{\mathrm{dp}}+\Delta \mathrm{t}_{\mathrm{dp}}$

where $t_{d p}$ is the standard duration of preparation for intended use (at the beginning of a working day or between cycles of intended use), hour; $t_{r}$ is a mean time to recovery, hour.

Let us carry out the mathematical modeling of dependencies. Using the numerical values and products technical characteristics, we have dependency graphs.

Let us evaluate the actual readiness level of Product 1 by using the following numerical values:

$$
\mathrm{K}_{\mathrm{p}}=\frac{1}{m} \sum_{i=1}^{m} \frac{n_{i}}{N}
$$

where $\mathrm{T}$ is the duration of an operation period during which the actual number of serviceable products is analyzed at the specified periodicity $t$; $\mathrm{m}=[\mathrm{T} / \mathrm{t}]$ is the number of analysis cycles (the square brackets denote a whole part of division [15/t]); 30 days are one month, a year is 365 days, then $\mathrm{t}=$ $0.082) ; \mathrm{n}$ is the number of serviceable products at 
the $\mathrm{i}$-th cycle equal to $1 ; \mathrm{N}$ is the total number of products in a sample (group) equal to 1.

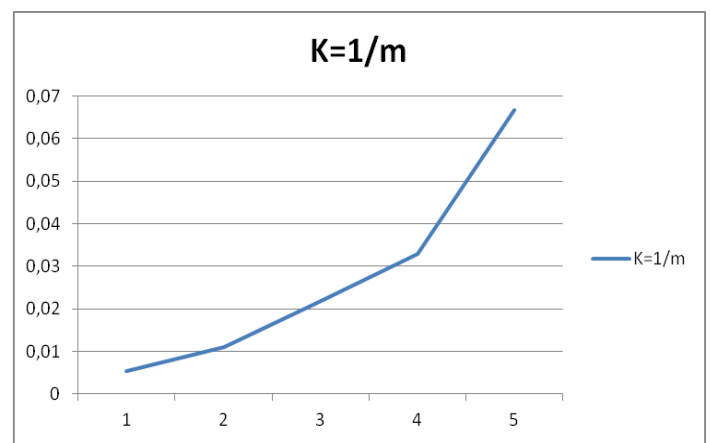

Fig. 1: Dependence of the actual product readiness level on the operation period duration according to the formula (8).
Table 1. Calculation of the actual product readiness level dependence on the operation period duration (Fig. 1).

\begin{tabular}{|c|c|c|c|c|}
\hline $\begin{array}{l}\mathrm{T} \\
\text { (years) }\end{array}$ & $\begin{array}{l}\text { conversio } \\
\mathrm{n} \text { into } \\
\text { days }\end{array}$ & $\begin{array}{l}\mathrm{t}=30 \\
\text { days }\end{array}$ & $\begin{array}{c}\mathrm{m}= \\
\mathrm{T} / \mathrm{t}\end{array}$ & $\mathrm{K}=$ \\
\hline 15 & 5475 & 30 & 182.5 & 0.005479 \\
\hline 15 & 5475 & 60 & 91.25 & 0.010959 \\
\hline 15 & 5475 & 120 & 45.625 & 0.021918 \\
\hline 15 & 5475 & 180 & 30.416 & 0.032877 \\
\hline 15 & 5475 & 365 & 15 & 0.066667 \\
\hline
\end{tabular}

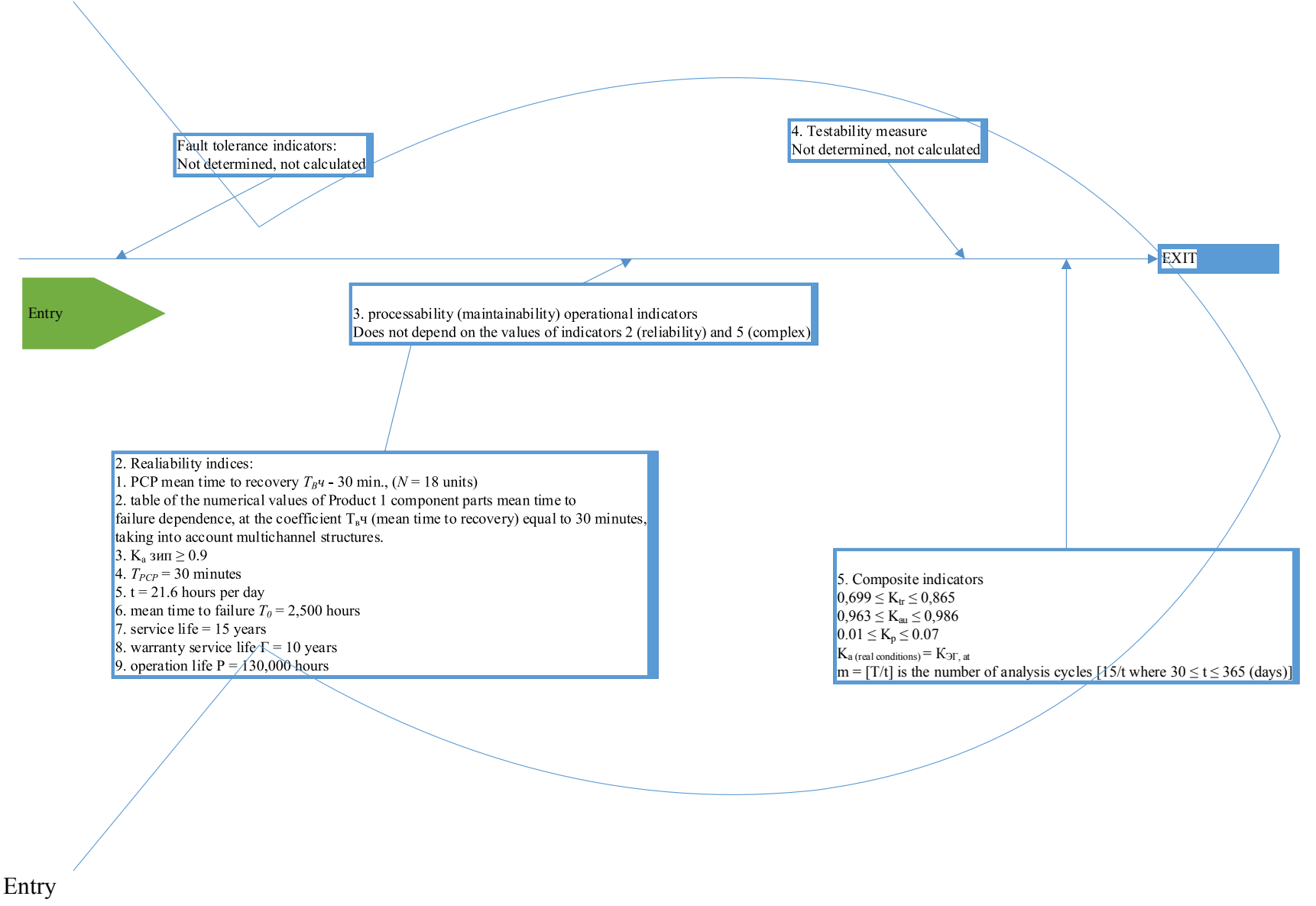

1. Fault tolerance indicators:

Not determined, not calculated

2. Realiability indices:

1. PCP mean time to recovery $T_{B} \varphi-30 \mathrm{~min} .,(N=18$ units $)$

2. table of the numerical values of Product 1 component parts mean time to failure dependence, at the coefficient $\mathrm{T}_{\mathrm{B}} \mathrm{Y}$ (mean time to recovery) equal to 30 minutes, taking into account multichannel structures.

3. Ка зип $\geq 0.9$

4. $T_{P C P}=30$ minutes

5. $\mathrm{t}=21.6$ hours per day

6. mean time to failure $T_{0}=2,500$ hours

7. service life $=15$ years

8. warranty service life $\Gamma=10$ years

9. operation life $\mathrm{P}=130,000$ hours 
3. processability (maintainability) operational indicators

Does not depend on the values of indicators 2 (reliability) and 5 (complex)

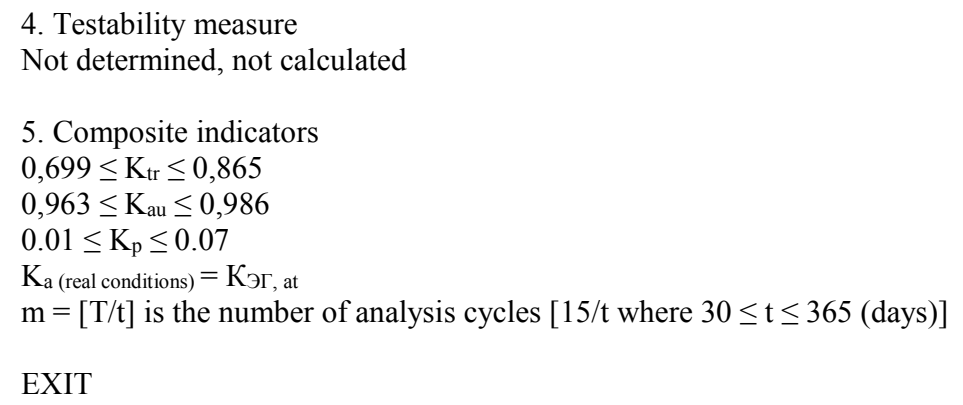

Fig. 2: Dependence of the actual product readiness level on the operation period duration according to the formula (8).

The first calculation indicates that if the product operation period is 15 years, and the analysis cycles are $30 \leq \mathbf{m} \leq 365$, the actual readiness level increases. We determined the maximum possible product readiness analysis cycle once a year, with a 15 -year product operation guarantee.

Using mathematical modeling, we will analyze the dependencies of the Technical Readiness Coefficient depending on the failure-free operation and labor intensity of maintenance and repair according to the formulas (2)-(5). Mathematical modeling of a large number of indicators cannot be displayed by one graph. In this case, the Ishikawa method ("skeleton of fish") is used, a method of systematic analysis for the visualization of data and relations.

Parameter input (left), output data (right). Parameters are arranged from left to right in order of importance - the formulas (2)-(5). To clarify, the parameters can be written inside the "skeleton of fish".

Table 2. Calculation of product recovery probability at a given time (Fig. 3)

\begin{tabular}{|l|l|l|l|}
\hline \multicolumn{1}{|l|}{ Рв } & t & t в & \multicolumn{1}{|c|}{ } \\
\hline 0.632 & 0.5 & 0.5 & 30 \\
\hline 0.798 & 0.8 & 0.5 & 48 \\
\hline
\end{tabular}

The formulas (6) and (7) allow for a separate calculation of the product recovery probability at a given time, taking into account:

- the standard duration of preparation for intended use;
- the permissible time for delaying the start of product use;

- the possibility of intended use with individual product failures.

During modeling, we selected an intended product use standard duration interval from 30 to 48 minutes. With the time interval of 30 minutes and 48 minutes, the numerical probability values remain high, the difference in probability values $\mathrm{P}_{в}$ is as follows:

$$
0,798103482-0,632120559=0,165982923 \approx 0.2 \text {. }
$$

$\Delta \approx 0.2$ - this indicates that it is not advisable to change the established tactical and technical characteristics of the product. The parameters of product component parts mean time to recovery are equal to 30 minutes, it is not advisable to change them, a probability gain is low: $\Delta \approx 0.2$. Under an export contract, it is not allowed to increase the permissible time for delaying the start of intended product use since there is a risk of penalties for its downtime. It is legally difficult to prove and distinguish between the physical meaning of product downtime and that one due to the planned time allowed for the start of intended product use. A ratio of a risk price (penalties) and a time difference of 30 to 48 minutes is not comparable with the probability $\Delta \mathrm{PB}_{\mathrm{B}} \approx 0.2$. In other words, "the game is not worth the candle".

\section{Conclusion}

The author's mathematical modeling of knowledgeintensive products export costs involves calculating the integrated logistics support costs. Exporting countries require a high level of technical products efficiency. Mathematical tools are provided to ensure a high level of technical readiness. It has been established that "the more complex a 
knowledge-intensive products is, the higher the reliability of systems is". Reliability indices are basic and are calculated according to the formulas (1)-(8). Core indicators are used, then export of knowledge-intensive products energy costs is modelled: a system of technical and economic indicators and a cost value dependence: Maintenance and Repair, Material and Technical Maintenance, Business Model of AfterSales Service, Formation of the Cost of Insurance and Investment Management Strategy. The more complex a knowledge-intensive product is and the higher the systems reliability is, the higher the total cost of integrated logistics support is. The author developed a set of integrated logistical support measures for knowledge-intensive products. Scientific research confirms the hypothesis of feasibility of exporting knowledge-intensive products only with high reliability and efficiency factors. The study is original, financial university higher doctorate. Mathematical modeling is carried out by author at the Faculty of Information Technologies of Russian State Social University, Moscow. The numerical values of tactical and technical characteristics belong to a real knowledgeintensive product. Mathematical modeling using artificial intelligence algorithms was considered in the previous work of the author [6]. The theory of economic doctrines and the horizons of the Russian economy were considered in the works of Kleiner G.B. [7- 10]. The author developed a set of integrated logistical support measures for knowledge-intensive products.

\section{References:}

[1] Alymov N., Rakhimzhanova A. Kh., Naizagaraeva A.A., Mimenbayeva A.B, 2015. Some questions of estimating the survivability index of complex systems // Bulletin of the Kazakh Agrotechnical University named after S. Seifullin 1 (84):148-157.

[2] Agafonov V.A., Yerznkyan B.A., 2021. System principles of strategic management improvement: institutional aspect // Economic Science of Modern Russia, (2): 57-71.

[3] Boitsov, M.S., Fedorov, A.S., Karavainikov, V.M. Energy Costs as a Manageable Economic Category (KGTU, City of Kostroma, Russian Federation) $\mathrm{http}: / /$ sciencebsea.narod.ru/2011/ekonom_2011_1/boicov_en ergetik.htm

[4] Ruzhinskaya, T.I. (2017). The Problems of the Russian Foreign Trade at the Present Stage. International Economic Relations: Pluralism of
Opinions in the Era of Changes]: a multiauthored monograph, endorsed by and with an introduction by Revenko L.S.; Moscow State Institute of International Relations of the Ministry of Foreign Affairs, Russia, Department of International Economic Relations and Foreign Economic Relations. Moscow, MGIMO-University, 493-504.

[5] Lipsky, E.A., Yankevich, A.A., Fertman Yankevich, A.A., Fertman. (2007). Logistics Support of Technical Systems in Military Products "REM" 5.

[6] Veretekhina S. V., 2021. Mathematical support of artificial intelligence algorithms in processing reflected satellite signals // Instruments and Systems. Management, control, diagnostics, 2:33-37.

[7] Kleiner G.B., 2015. System balance of the economy: methods of analysis and measurement // Strategic planning and development of enterprises. Section 1. Materials of the Sixteenth All-Russian Symposium. Edited by chl. - corr. RAS G. B. Kleiner. M.: TSEMI RAS: 74-78.

[8] Kleiner G. B., 2015. The economics of oil the economics of knowledge - the economics of thought: horizons of the Russian economy / / Scientific Works of the Free Economic Society of Russia, 196: 291-301.

[9] Kleiner G.B., 2015. Stability of the Russian economy in the mirror of system economic theory (Part 1) // Voprosy ekonomiki 1:107123.

[10] Kleiner G.B., 2016. Stability of the Russian economy in the mirror of system economic theory (Part 2) / / Voprosy ekonomiki 1:117138.

\section{Creative Commons Attribution License 4.0 (Attribution 4.0 International, CC BY 4.0)}

This article is published under the terms of the Creative Commons Attribution License 4.0 https://creativecommons.org/licenses/by/4.0/deed.en US 